\title{
A Retrospective Analysis about the Italy Emilia M6.0 Earthquake Prediction
}

\author{
Guangmeng Guo \\ Remote Sensing Center, Nanyang Normal University, Nanyang, China \\ Email: guogm@igsnrr.ac.cn
}

How to cite this paper: Guo, G.M. (2021) A Retrospective Analysis about the Italy Emilia M6.0 Earthquake Prediction. Open Journal of Earthquake Research, 10, 68-74. https://doi.org/10.4236/ojer.2021.102005

Received: March 19, 2021

Accepted: May 7, 2021

Published: May 10, 2021

Copyright () 2021 by author(s) and Scientific Research Publishing Inc. This work is licensed under the Creative Commons Attribution International License (CC BY 4.0).

http://creativecommons.org/licenses/by/4.0/

\begin{abstract}
Cloud anomaly is a new kind of earthquake precursor that is still in the great controversy. Here we report an example of earthquake prediction based on cloud satellite anomaly. According to the cloud anomaly that appeared over eastern Italy on 21-23 April 2012, we made a prediction to Italy National Institute of Geophysics and Volcanology (INGV) that there will be a M5.5 M6.0 earthquake in Italy in 30 days. Finally, the M6.0 quake occurred in northern Italy on 20 May 2012 and this verified our prediction. In this paper we extend the cloud image data from 2010 to 2013 and found 23 cloud anomalies totally, among them only the duration of the cloud on April 21-23 2012 exceed the 2 times, even 3 times of standard deviation threshold and it can be considered as a significant anomaly. Our analysis shows that the quake's date and magnitude can be estimated accurately with the formula, and the epicenter can be estimated with the temperature anomaly method with $100-200 \mathrm{~km}$ error. This paper shows a promising method in earthquake prediction, of course it is only one example, and it still needs more examples to verify this method.
\end{abstract}

\section{Keywords}

Earthquake Prediction, Italy, Cloud Anomaly

\section{Introduction}

In 1997 Russian scientist Morozova reported some unusual linear clouds above fracture regions [1]. This is the first report about cloud anomalies that may be related to active fault systems. Shou reported linear cloud formations 32 days prior to the 17 August 1997 M7.4 Izmit, Turkey earthquake and an unusual cloud that looks like emitted from a point source 5 days prior to the 26 December 2003 M6.6 Bam, Iran earthquake [2]. Guo and Wang studied two strong Iran M6.0 and M6.4 earthquakes and found linear clouds about two months before 
these earthquakes [3]. Wu et al. reported two linear clouds which pointed to the epicenter prior to the 12 May 2008 M7.9 Wenchuan earthquake of China [4]. These studies show that some relation might exist between clouds and earthquakes, while the mechanism of earthquake clouds is still not yet well understood.

On 22 April 2012 a linear cloud appeared over eastern Italy (Figure 1). According to this cloud anomaly, we make this prediction to INGV: "There will be a $M=5.5-M=6.0$ quake in Italy. If $M=5.5$, it is about in 10 days. If $M=6.0$, it is in 30 days. I am trying to reduce the location error, but my data is limited" [5]. In this prediction we did not give specific bounds on epicenter location, because the cloud is very long, it is about $400 \mathrm{~km}$ and it is impossible to get a point location from this long cloud.

On 20 May 2012 a M6.0 earthquake occurred at $44.800^{\circ} \mathrm{N}, 11.192^{\circ} \mathrm{E}$ in north Italy, and a M5.8 earthquake occurred at $44.814^{\circ} \mathrm{N}, 11.079^{\circ} \mathrm{E}$ on 29 May 2012 reported by USGS. The M6.0 quake is the largest one in Italy since the M6.3 L'Aquila quake in April 2009. The facts verified our prediction. We searched the relevant references from May 2012 to May 2020 and found no similar predictions reported in the world except ours. After our paper was published some scientists such as Thomas et al. suspected this method, and they considered that there is no clear relation between clouds and earthquakes [6]. A problem of Thomas' research is that they just checked the relation between clouds and $M \geq$ 5 earthquakes, while they did not check the $M \geq 4.0, M \geq 4.5, M \geq 5.5, M \geq 6.0$ earthquakes respectively, so their conclusion is partial and not convincing. Here we reanalyze this prediction and get some new results.

\section{Analysis of Four Years Data}

In the paper published in 2013 we just showed the clouds in April, 2012 [5]. Someone suspected that the period was too short. According to Thomas's suggestion and data [6], we extended the period to four years, namely from 2010-1-1 to 2013-12-31, and found many similar linear clouds as Thomas did. The clouds' dates are listed in Table 1 . We calculated the mean value $(\mu)$ and the standard

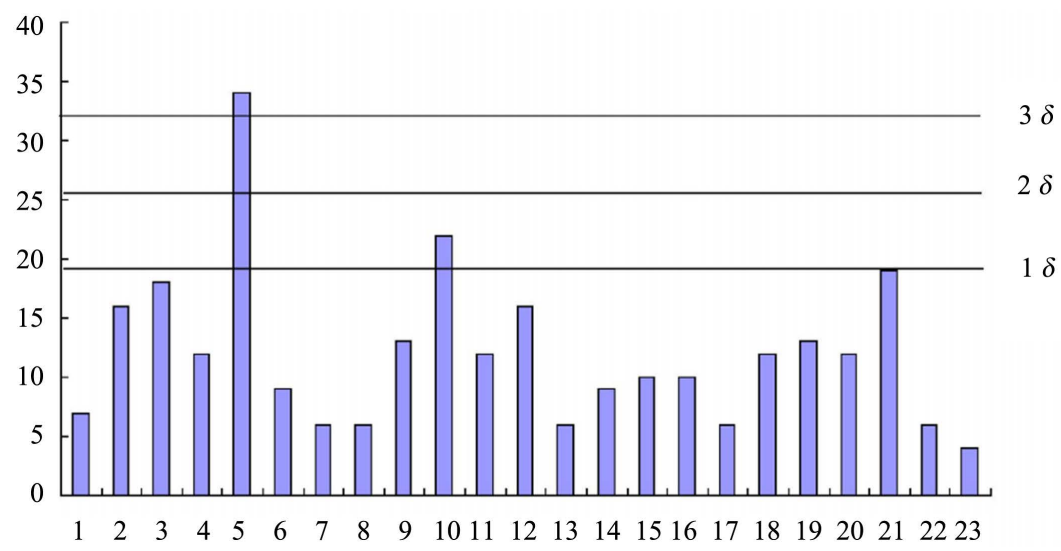

Figure 1. Maps for the 23 clouds duration, the lines of $\mu+1 \delta, \mu+2 \delta, \mu+3 \delta$ are plotted. 
Table 1. Cloud anomalies and their duration in 2010-2013.

\begin{tabular}{|c|c|c|c|}
\hline No. & Date & Year & Duration (hours) \\
\hline 1 & 8-Jun & 2011 & 7 \\
\hline 2 & 5-Dec & 2011 & 16 \\
\hline 3 & 14-Dec & 2011 & 18 \\
\hline 4 & 15-Dec & 2011 & 12 \\
\hline 5 & 21-23 Apr & 2012 & 34 \\
\hline 6 & 6-May & 2012 & 9 \\
\hline 7 & 14-Aug & 2012 & 6 \\
\hline 8 & 17-Aug & 2012 & 6 \\
\hline 9 & 24-25 Sep & 2012 & 13 \\
\hline 10 & 27-Sep & 2012 & 22 \\
\hline 11 & $14-15$ Oct & 2012 & 12 \\
\hline 12 & 25-Dec & 2012 & 16 \\
\hline 13 & 10-Apr & 2013 & 6 \\
\hline 14 & 29-May & 2013 & 9 \\
\hline 15 & 7-8 Aug & 2013 & 10 \\
\hline 16 & $10-$ Oct & 2013 & 10 \\
\hline 17 & 13 -Oct & 2013 & 6 \\
\hline 18 & $28-29$ Oct & 2013 & 12 \\
\hline 19 & 3-Nov & 2013 & 13 \\
\hline 20 & 4 -Nov & 2013 & 12 \\
\hline 21 & 9-10 Nov & 2013 & 19 \\
\hline 22 & 20-Nov & 2013 & 6 \\
\hline 23 & 29-Dec & 2013 & 4 \\
\hline
\end{tabular}

deviation ( $\delta$ ) of the duration for the 23 cloud anomalies, and found that only the duration of the cloud on April 21-23 2012 is bigger than $2 \delta$, it is also bigger than $3 \delta$ (Figure 1 ) which means a strong anomaly. In the 4 years it is the only anomaly which is bigger than $3 \delta$ threshold and 28 days later a M6.0 earthquake occurred in north Italy, which is the only one bigger than (or equal to) M6.0 from May 2009 to May 2016 in Italy. That means this cloud anomaly is related with Emilia M6.0 earthquake with very high confidence. This does not conflict with Thomas's conclusion, because they just checked the relation between clouds and the earthquakes with $M \geq 5.0$, while we only focused on the strong quakes ( $M \geq$ 6.0). This gives another benefit because strong earthquakes lead to serious damage than medium earthquakes.

\section{Method of the Earthquake Date Prediction}

In our original prediction we give 10 - 30 days for this forthcoming quake. It is based on our experience that a M6.0 quake comes usually within 1 month. This 
is a very rough estimation. For the accurate earthquake occurrence date, Doda et al. suggested that strong earthquakes usually take place on the 7 , or 14 , or 21 days approximately after geoeffective manifestations of the Sun eruptions [7]. So the following empirical Formula (1) is developed based on statistical data analysis to determine the earthquake date:

$$
d_{1}=d_{0}+(7 \text { or } 14 \text { or } 21)+27 n
$$

where $d_{0}$ is the day of Sun activity manifestation with the number of cycles $n=0$, 1 or $2, d_{1}$ is the earthquake day, and the error of this formula is about 2 days [7].

The first cloud anomaly appeared on 4 - 22 (Figure 2), and the Disturbance storm time index (Dst) is -110nt which showed a strong geomagnetic disturbance on 4 - 23 (Figure 3). They can be considered as different start point for Formula (1). Then the possible earthquake dates are calculated with Formula (1) and the results (Table 2) show that $5-6$ to $5-7,5-20$ to $5-21$ are the most dangerous dates that the earthquake will most likely happen. The final fact is that the earthquake happened on 5 - 20. This shows that our calculation is very close to the facts. If we do not use 7 or 14 days period, and suppose $n=1$ in Formula (1), then the result is $4-22$ plus 27 days, namely 5 - 19. It is also very close to the quake date.



Figure 2. Clouds with linear edge over east Italy on 22 April, 2012 in the white circle. The red cross means the M6.0 earthquake epicenter occurred on 20 May 2012.

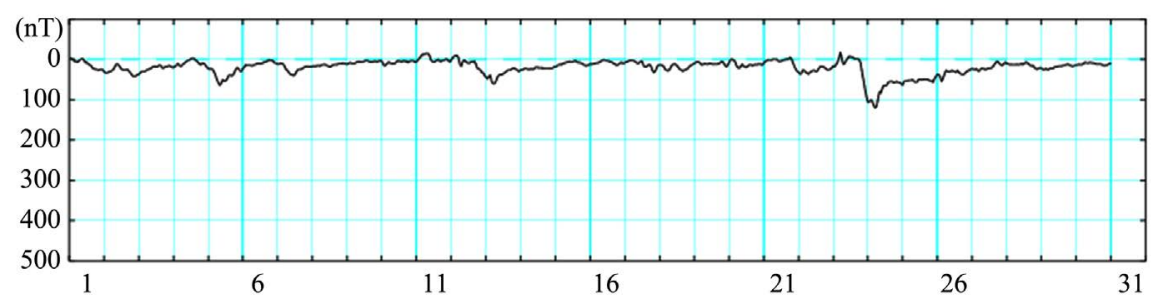

Figure 3. Dst index of April, 2012 shows a strong Dst change occurred on 4 - 23 (Dst data is from http://wdc.kugi.kyoto-u.ac.jp). 
Table 2. Possible earthquake dates calculation based on the date of cloud anomaly and geomagnetic storm.

\begin{tabular}{|c|c|c|c|c|c|}
\hline $\begin{array}{l}4 \text { - } 22 \text { cloud with } \\
7 \text { days cycle }\end{array}$ & $4-29$ & $5-6$ & $5-13$ & $5-20$ & $5-27$ \\
\hline $\begin{array}{l}4 \text { - } 22 \text { cloud with } \\
14 \text { days cycle }\end{array}$ & & $5-6$ & & $5-20$ & \\
\hline $\begin{array}{c}4 \text { - } 23 \text { geomagnetic } \\
\text { Storm with - } 7 \text { days cycle }\end{array}$ & $4-30$ & $5-7$ & $5-14$ & $5-21$ & $5-28$ \\
\hline $\begin{array}{c}4-23 \text { geomagnetic storm } \\
\text { with } 14 \text { days cycle }\end{array}$ & & $5-7$ & & $5-21$ & \\
\hline
\end{tabular}

\section{Method of the Earthquake Magnitude Prediction}

In our original prediction magnitude estimation is made based on experience. According to Doda's method, the quake's magnitude can be estimated with this formula

$$
M=\ln L
$$

where $M$ is magnitude and $L$ is the cloud's length [7]. Here $L$ is about $400 \mathrm{~km}$, so $M=\ln 400=5.9$. Finally the magnitude of the quake occurred on May 20, 2012 is M6.0, which means Formula (2) shows a good performance.

\section{Method of Epicenter Location Prediction}

Our original location estimation is whole Italy. Because it is our first time to study Italy and we know nothing about Italy geology structure and seismic activity. The cloud anomaly is about $400 \mathrm{~km}$ long and it is difficult to get a point epicenter location from this long cloud. Qin et al. investigated the surface skin temperature in Italy in April and May of 1979-2012, and found a spot-shaped thermal anomaly near the epicenters in the night of May 12, 2012 with high confidence [8] (Figure 4). With this method, the epicenter location estimation error can be limited within $100-200 \mathrm{~km}$ approximately. Compared with our original location estimation, the location error has been reduced greatly. Note that this thermal anomaly is in the night of May 12, it is 7 - 8 days before the earthquake which is very close to the 7 days period in Formula (1).

\section{Result and Discussion}

In this paper we extend the cloud images period from one month (April 2012) to four years (2010-2013), and find 23 linear clouds totally. With the 2 times or 3 times standard deviation criteria, only the clouds anomaly on 22 April is significant in four years, and 28 days later a M6.0 quake hit Italy. This quake is also the only one bigger than (or equal to) M6.0 in Italy from May 2009 to May 2016. These facts show that the cloud anomaly of April 22 may be related to the Emilia earthquake with high confidence. Harrison et al. used atmospheric-lithosphereionosphere charge exchange model and suggested a possible relationship between earthquakes and clouds [9]. For the Emilia earthquake, our retrospective 


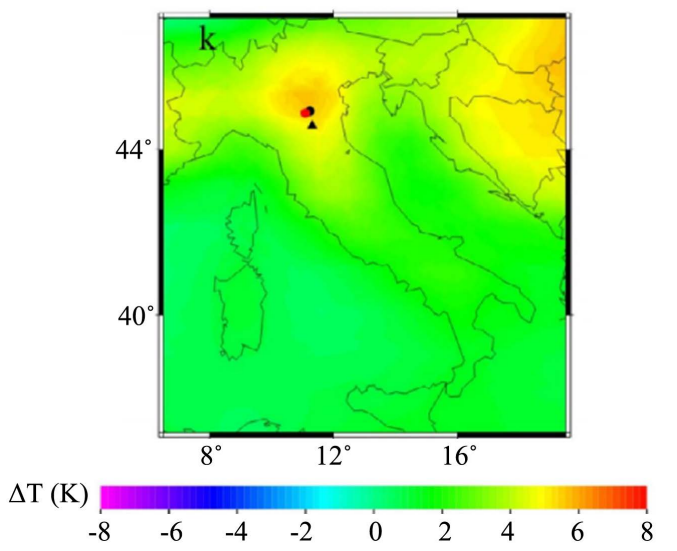

Figure 4. A thermal anomaly appeared near the epicenter in the night of May 12, 2012 [8].

analysis shows that the date and the magnitude can be well predicted according to Doda's method and the epicenter location can be estimated with Qin's method. Compared with the world-famous Parkfield earthquake prediction experiment, the USGS scientists gave 8 years time window, spent millions of dollars and hundreds of people, and try to predict a M6.0 earthquake in Parkfield, California, while finally they failed [10]. This fact shows that earthquake prediction is extremely difficult, while our methods succeed and show a promising future in earthquake research. Of course we have just one example, and more examples are needed to validate this method.

\section{Acknowledgements}

The satellite data is provided by https://en.sat24.com/en, and Dst data is provided by http://wdc.kugi.kyoto-u.ac.jp. Their help is greatly appreciated.

\section{Conflicts of Interest}

The author declares no conflicts of interest regarding the publication of this paper.

\section{References}

[1] Morozova, L.I. (1997) Dynamics of Cloudy Anomalies above Fracture Regions during Natural and Anthropogenically Caused Seismic Activities. Fizika Zemli, 9, 94-96.

[2] Shou, Z.H. (1999) Earthquake Clouds, a Reliable Precursor. Science \& Utopya, 64, 53-57. (In Turkish)

[3] Guo, G.M. and Wang, B. (2008) Cloud Anomaly before Iran Earthquake. International Journal of Remote Sensing, 29, 1921-1928. https://doi.org/10.1080/01431160701373762

[4] Wu, L.X., Li, J.P. and Liu, S.J. (2009) Space Observed Two Abnormal Linear Clouds before Wenchuan Earthquake. Proceedings of the 3 rd IASME/WSEAS International Conference on Geology and Seismology, Cambridge, UK, 138-143.

[5] Guo, G.M. and Yang, J. (2013) Three Attempts of Earthquake Prediction with Satellite Cloud Images. Natural Hazards and Earth System Science, 13, 91-95. 
https://doi.org/10.5194/nhess-13-91-2013

[6] Thomas, J.N., Masci, F. and Love, J.J. (2015) On a Report That the 2012 M6.0 Earthquake in Italy Was Predicted after Seeing an Unusual Cloud Formation. Natural Hazards and Earth System Science, 15, 1061-1068.

https://doi.org/10.5194/nhess-15-1061-2015

[7] Doda, L.N., Dushin, V.R., Natyaganov, V.L., Smirnov, N.N. and Stepanov, I.V. (2011) Earthquakes Forecasts Following Space- and Ground-Based Monitoring. Acta Astronautica, 69, 18-23. https://doi.org/10.1016/j.actaastro.2011.02.012

[8] Qin, K., Wu, L.X., De Santis, A. and Cianchini G. (2012) Preliminary Analysis of Surface Temperature Anomalies That Preceded the Two Major Emilia 2012 Earthquakes (Italy). Annals of Geophysics, 55, 823-828.

[9] Harrison, R.G., Aplin, K.L. and Rycroft, M.J. (2014) Earthquake-Cloud Coupling through the Global Atmospheric Electric Circuit. Natural Hazards and Earth System Science, 14, 773-777. https://doi.org/10.5194/nhess-14-773-2014

[10] Bakun, W.H. and Lindh, A.G. (1985) The Parkfield, California, Earthquake Prediction Experiment. Science, 229, 619-624.

https://doi.org/10.1126/science.229.4714.619 